\title{
On the Systematic Downside Risk Measure: A Note
}

\author{
Yin-Ching $\operatorname{Jan}^{1}$ \\ ${ }^{1}$ Department of Distributuion Management, National Chin-Yi University of Technology, Taiwan, R.O.C. \\ Correspondence: Yin-Ching Jan, Department of Distributuion Management, National Chin-Yi University of \\ Technology, Taiwan, R.O.C. Tel: 886-4-23924505. \\ Received: July 14, 2016 \\ Accepted: August 4, 2016 \\ Online Published: October 8, 2016 \\ doi:10.5430/ijfr.v7n5p51 \\ URL: http://dx.doi.org/10.5430/ijfr.v7n5p51
}

\begin{abstract}
This note introduces a heuristic systematic downside risk measure. The previous return is used as benchmark of next period return to calculated semi-covariance and semi-variance. The new downside beta can avoid subjective measurements of benchmark for different investors. We demonstrate that the new downside beta is more suitable to investor risk conception.
\end{abstract}

Keywords: systematic downside risk, downside beta

\section{Introduction}

Risk is not measurable uncertainty nor volatility. Holton (2004) stated that risk is exposure to uncertainty. Recent study of Lemos (2016) separated risk into three part concept. Risk is the potential that events may have an unexpected and noteworthy impact on results, risk is an uncertainty, and risk is the perception of risk. The multiple risk concepts may help to explain why idiosyncratic risk can improve power to explain expected asset return. Among others, see Malkie and Xu (1997) and Xu and Malkiel (2004) for example. By use of experimental study, Veld and Veld-Merkoulova (2008) found that most investors implicitly use more than one risk measure. Furthermore, semi-variance of returns is most popular for those investors who systematically perceive risk according to the same risk measure. In the pioneering work of Markowitz (1959), he suggested use of semi-variance as a plausible measure of risk. Nevertheless, he used conventional variance as a risk measure to model the return/risk framework, because of its simplicity and ease of calculation. The return/risk framework used by variance and beta had led to lots of debates. See the work of Campbell (2000).

Many scholars and practitioners have suggested downside risk is better than variance and beta. For example, Balzer (1995) review the measurement of investment risk, and recommend the use of relative semi-variance for the investment decisions. Nawrocki (1999) also review the history of downside risk measure, and suggest the use of downside risk. The measurement of systematic downside risk had been proposed by Markowitz (1959) and Hogan and Warren (1974). Bawa and Lindenberg (1977) generalize the Hogan and Warren framework and show their model can explain the return/risk at least as well as the Capital Asset Pricing Model (CAPM). Estrada (2002) and Ang et al. (2006) suggested alternative specifications of systematic downside risk. They also showed that their downside betas are better than beta and the CAPM empirically. Artavanis (2014) discussed the appropriate methodology for the estimation of systematic downside risk. He found that the Hogan and Warren (1974) approach is the only one consistent with the original downside risk framework as defined by Markowitz. Moreover, the Hogan and Warren downside beta dominates other specifications of downside risk empirically. However, the Hogan and Warren specification need threshold return to calculate the systematic downside risk. If each investor's threshold return is different, it would result in different risk measures. In addition, all the three specification developed by Hogan and Warren, Estrada, and Ang et al. may not distinguish adequately the systematic downside risk between boom and recession state of economy. In this note, I suggest a new systematic downside risk, which uses previous return as benchmark of next period return.

\section{Systematic Downside Risk Measure}

There are three important unconditional downside betas according to the work of Artavanis (2014). Artavanis proposed a limit version of the framework of Hogan and Warren (1974). Specifically, the modified version of Hogan and Warren can be written as: 


$$
\beta_{\mathrm{i}, \mathrm{HW}}^{-}=\frac{\sum_{\mathrm{t}=1}^{\mathrm{T}}\left[\left(\mathrm{R}_{\mathrm{it}}-\mathrm{R}_{\mathrm{T}}\right) \cdot \min \left\{0,\left(\mathrm{R}_{\mathrm{mt}}-\mathrm{R}_{\mathrm{T}}\right)\right\}\right]}{\sum_{\mathrm{t}=1}^{\mathrm{T}}\left[\min \left\{0,\left(\mathrm{R}_{\mathrm{mt}}-\mathrm{R}_{\mathrm{T}}\right)\right]^{2}\right.}
$$

where $R_{i t}$ and $R_{m t}$ are the return of asset $i$ and market at period $t, R_{T}$ is the threshold return, $T$ is the sample size, and $\min \{\because$,$\} is minimum operator.$

In the modified version, risk only occurs when the market underperforms the threshold return. As a result, one asset systematic risk would be less when it outperforms the threshold return.

Estrada (2002) introduces a heuristic approach, according to which downside covariance is estimated by considering only observations for which both asset and market underperform the threshold return. That is.

$$
\beta_{\mathrm{i}, \mathrm{EST}}^{-}=\frac{\sum_{\mathrm{t}=1}^{\mathrm{T}}\left[\min \left\{0,\left(\mathrm{R}_{\mathrm{it}}-\mathrm{R}_{\mathrm{T}}\right)\right\} \cdot \min \left\{0,\left(\mathrm{R}_{\mathrm{mt}}-\mathrm{R}_{\mathrm{T}}\right)\right\}\right]}{\sum_{\mathrm{t}=1}^{\mathrm{T}}\left[\min \left\{0,\left(\mathrm{R}_{\mathrm{mt}}-\mathrm{R}_{\mathrm{T}}\right)\right]^{2}\right.}
$$

Ang et al. (2006) use a different formula to estimate systematic downside risk. The downside beta is similar to the conventional beta, which defined as the ratio of the covariance between the asset and the market over the market variance. However, the downside beta is computed only when the market underperforms the threshold return.

$$
\beta_{\mathrm{i}, \mathrm{ACX}}^{-}=\frac{\sum_{\mathrm{t}=1}^{\mathrm{T}}\left[\left(\mathrm{R}_{\mathrm{it}}-\overline{\mathrm{R}}_{\mathrm{i}}\right) \cdot\left(\mathrm{R}_{\mathrm{mt}}-\overline{\mathrm{R}}_{\mathrm{m}}\right) / \mathrm{R}_{\mathrm{mt}}<\mathrm{R}_{\mathrm{T}}\right]}{\sum_{\mathrm{t}=1}^{\mathrm{T}}\left[\left(\mathrm{R}_{\mathrm{mt}}-\overline{\mathrm{R}}_{\mathrm{m}}\right) / \mathrm{R}_{\mathrm{mt}}<\mathrm{R}_{\mathrm{T}}\right]^{2}}
$$

where $\overline{\mathrm{R}}_{\mathrm{i}}$ and $\overline{\mathrm{R}}_{\mathrm{m}}$ are the average return of asset $i$ and market.

Artavanis (2014) applied Fama-MacBeth regressions to examine the relationship between returns and the three downside betas. He found that the modified Hogan and Warren downside beta dominates the other two downside betas. However, the modified Hogan and Warren downside beta need a threshold return, and can't distinguish the downside beta of an asset with upward market return and an asset with downward market return. Take two fictitious assets $\mathrm{A}$ and $\mathrm{B}$ for example. The returns of asset A, B, and market are fictitious, and shown in Figure 1. Their time-series returns are shown in Appendix.
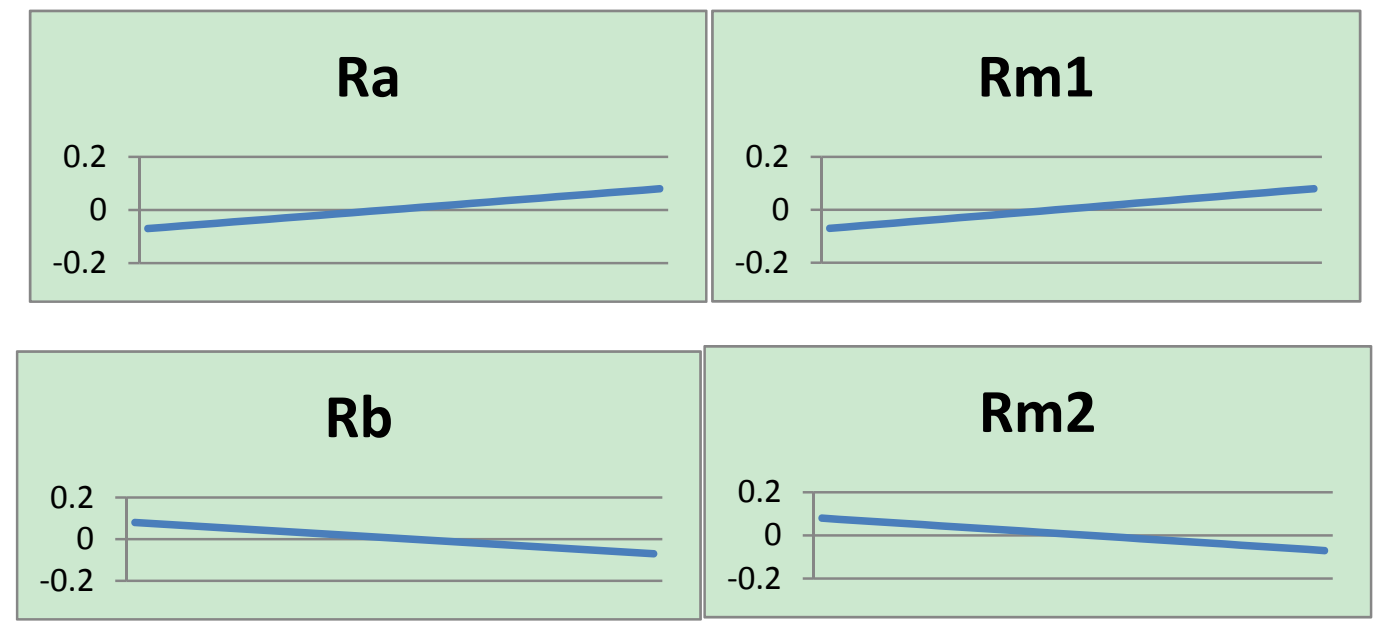

Figure 1. Same pattern of time series returns of asset and market

The downside betas of asset A and B calculated by the modified Hogan and Warren, Estrada, and Ang et al. are all equal to 1, and shown in Table 1. However, the asset B would be thought riskier than the asset A by investors, because the time series patterns of B and market are downward, while those of A and market are upward. The investors not only dislike downside volatility, but downward trend of return. The three downside betas cannot distinguish the systematic risk of asset A with B. 
Table 1. Downside betas calculated by different specification

\begin{tabular}{ccccc}
\hline Asset & $\beta_{\mathrm{HW}}^{-}$ & $\beta_{\mathrm{EST}}^{-}$ & $\beta_{\mathrm{ACX}}^{-}$ & $\beta_{\text {JAN }}^{-}$ \\
\hline $\mathrm{A}$ & 1.0 & 1.0 & 1.0 & 0.0 \\
\hline $\mathrm{B}$ & 1.0 & 1.0 & 1.0 & 1.0 \\
\hline $\mathrm{C}$ & -0.83 & 0.0 & -1.0 & -1.0 \\
\hline $\mathrm{D}$ & -0.83 & 0.0 & -1.0 & 0.0
\end{tabular}

The threshold return used to calculate downside beta is equal to zero. There are four downside betas, including modified Hogan and Warren $\left(\beta_{\mathrm{HW}}^{-}\right)$, Estrada $\left(\beta_{\mathrm{EST}}^{-}\right)$, Ang et al. $\left(\beta_{\mathrm{ACX}}^{-}\right)$, and a heuristic approach introduced in this note $\left(\beta_{\text {JAN }}^{-}\right)$. The assets $A, B, C, D$, and market are fictitious. Their time-series returns are shown in Appendix.

The three downside betas can't distinguish a reverse pattern of two time series return either. Take two other fictitious assets $\mathrm{C}$ and $\mathrm{D}$ for example. The return of asset $\mathrm{C}$ is upward with market declining, while asset $\mathrm{D}$ is downward with market growing. The returns of asset C, D, and market are shown in Figure 2. Table 1 shows the downside betas of asset $\mathrm{C}$ and $\mathrm{D}$. The downside betas of $\mathrm{C}$ and $\mathrm{D}$ calculated by the modified Hogan and Warren are equal to -0.83 , Estrada are equal to zero, and Ang et al. are equal to -1. However, the market return is upward when we calculate the downside beta of asset $\mathrm{C}$, while the market return and asset D are opposite. All of the downside betas are calculated by the downside covariance of asset with market over the downside variance of market. The downside beta can be used to measure the contribution of one asset's risk to the downside variance of market. As a result, we can see that the downside beta of asset $\mathrm{D}$ would be riskier than $\mathrm{C}$, because including asset $\mathrm{C}$ can diversify the risk of market.
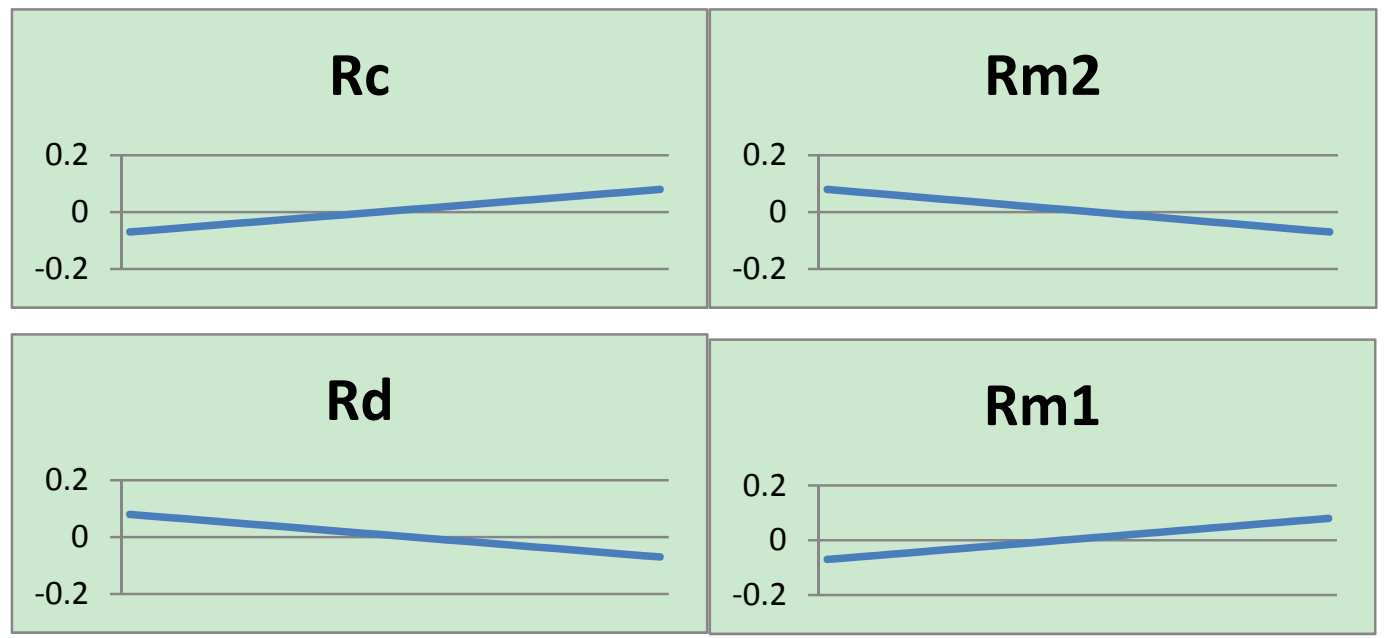

Figure 2. Reverse pattern of time series returns of two asset and market

Jan and Wang (2012) suggested use of martingale variance (MVAR ) and martingale semi-variance (MSVAR ) instead of variance and semi-variance to measure idiosyncratic risk. The martingale variance and martingale semi-variance are calculated as follows:

$$
\begin{aligned}
\text { MVAR }= & \frac{\sum_{t=1}^{T}\left(R_{i t}-R_{i, t-1}\right)^{2}}{T} \\
& =\frac{2\left\{\left(\sum_{\mathrm{t}=1}^{\mathrm{T}} \mathrm{R}_{\mathrm{it}}^{2}-E(R)^{2}\right)-\left(\sum_{t=1}^{T} R_{i t} R_{i, t-1}-E(R)^{2}\right)\right\}}{T} \\
& =2\left\{\operatorname{VAR}(R)-\operatorname{COV}\left(R_{i t}, R_{i, t-1}\right)\right\}
\end{aligned}
$$




$$
\operatorname{MSVAR}=\frac{\sum_{t=1}^{T}\left\{\operatorname{Min}\left(0, R_{i t}-R_{i, t-1}\right)\right\}^{2}}{T}
$$

where $E(\bullet)$ represents expectation operator. $V A R$ and $C O V$ are conventional variance and covariance operators, respectively. The expectation of next period return is previous return by the property of martingale. Therefore, they use previous return as benchmark of next period. We can see that the martingale variance and martingale semi-variance take the return's autocorrelation into account.

Following the martingale semi-variance, an asset's downside beta should be the contribution of martingale covariance of one's return with market over market's martingale semi-variance, That is.

$$
\beta_{\mathrm{i}, J A N}^{-}=\frac{\sum_{\mathrm{t}=1}^{\mathrm{T}}\left[\left(\mathrm{R}_{\mathrm{it}}-\mathrm{R}_{\mathrm{i}, \mathrm{t}-1}\right) \cdot \min \left\{0,\left(\mathrm{R}_{\mathrm{mt}}-\mathrm{R}_{\mathrm{m}, \mathrm{t}-1}\right)\right\}\right]}{\sum_{\mathrm{t}=1}^{\mathrm{T}}\left[\min \left\{0,\left(\mathrm{R}_{\mathrm{mt}}-\mathrm{R}_{\mathrm{m}, \mathrm{t}-1}\right)\right]\right]^{2}}
$$

The formula is similar to the modified Hogan and Warren, except use of previous return instead of threshold return. Form Table 1, we can see that the downside beta of asset $\mathrm{A}$ is equal to zero owing to the same upward return pattern of asset and market, while the downside beta of $\mathrm{B}$ is equal to 1.0 because of the same downward return pattern of asset and market. When the time series pattern of returns is opposite, we can see that the downside beta of $\mathrm{C}$ is equal to -1 , while D is equal to zero. The measurement would be more suitable to investor's risk conception.

\section{Conclusion}

Systematic downside risk has been proved its role in helping to explain expected asset return. The Hogan and Warren (1974) approach is not only consistent with the original downside risk framework as defined by Markowitz, but dominates other specifications of downside risk empirically. However, the Hogan and Warren specification need threshold return to calculate the systematic downside risk. Different investor would get different risk measure, if each investor's threshold return is different. In this note, I introduce a heuristic downside beta, which is based on the property of martingale. As a result, we can avoid the subjective benchmark return and get an objective risk measure. Moreover, we also demonstrate that the new risk measure is more suitable than the other downside betas developed by Hogan and Warren (1974), Estrada (2002), and Ang et al. (2006).

\section{Acknowledgement}

I am grateful for comments to the referee and editor. This research is funded by National Chin-Yi University of Technology.

\section{References}

Ang, A., Chen, J., \& Xing, Y. (2006). Downside risk, Review of Financial Studies, 19(4), 1191-1239. http://dx.doi.org/10.1093/rfs/hhj035

Artavanis, N. (2014). On the estimation of systematic downside risk. Retrieved from http://ssrn.com/abstract=2140184

Balzer, L. (1994). Measuring investment risk: A Review. Journal of Investing, 3(3), 47-58. http://dx.doi.org/10.3905/joi.3.3.47

Bawa, V., \& Lindenberg, E. (1977). Capital market equilibrium in a mean-lower partial moment framework. Journal of Financial Economics, 5, 189-200. http://dx.doi.org/10.1016/0304-405X(77)90017-4

Campbell, J. Y. (2000). Asset pricing at the millennium, Journal of Finance, 55(4), 1515-1567. http://dx.doi.org/10.1111/0022-1082.00260

Estrada, J. (2002). Systematic risk in emerging markets: the d-capm. Emerging Markets Review, 3(4), $365-379$. http://dx.doi.org/10.1016/S1566-0141(02)00042-0

Hogan. W., \& Warren, J. (1974). Towards the development of an equilibrium capital-market model based on semi-variance. Journal of Financial and Quantitative Analysis, 9, 1-11. http://dx.doi.org/10.2307/2329964

Holton, G. A. (2004). Defining risk. Financial Analysts Journal, 60(6), 19-25. http://dx.doi.org/10.2469/faj.v60.n6.2669

Jan, Y. C., \& Wang, J.M.C (2012). A note on idiosyncratic risk measure, Journal of Money, Investment and Banking, $25,119-123$.

Lemos, F. (2016). On risk - Building a definition. Retrieved from http://ssrn.com/abstract=2734050 
Malkiel, B., \& Xu, Y. (1997). Risk and return revisited, Journal of Portfolio Management, 23(3), 9-14. http://dx.doi.org/10.3905/jpm.1997.409608

Markowitz, H. (1959). Portfolio selection. Efficient diversification of investments. John Wiley \& Sons.

Nawrocko, D. (1999). A brief history of downside risk measures. Journal of Investing, 8(3), 9-25. http://dx.doi.org/10.3905/joi.1999.319365

Veld, C., \& Veld-Merkoulova, Y. V. (2008). The risk perceptions of individual investors, Journal of Economic Psychology, 29, 226-252. http://dx.doi.org/10.1016/j.joep.2007.07.001

Xu, Y., \& Malkiel, B. (2004). Idiosyncratic risk and security returns. AFA 2001 New Orleans Meetings. Retrieved from http://ssrn.com/abstract=255303

\section{Appendix}

All the average return and standard deviation of the four assets and market are equal $0.5 \%$ and $4.55 \%$, respectively.

\begin{tabular}{|c|c|c|c|c|c|}
\hline $\mathrm{Ra}$ & $\mathrm{Rb}$ & $\mathrm{Rc}$ & $\mathrm{Rd}$ & $\mathrm{Rm} 1$ & $\mathrm{Rm} 2$ \\
\hline-0.07 & 0.08 & -0.07 & 0.08 & -0.07 & 0.08 \\
\hline-0.065 & 0.075 & -0.065 & 0.075 & -0.065 & 0.075 \\
\hline-0.06 & 0.07 & -0.06 & 0.07 & -0.06 & 0.07 \\
\hline-0.055 & 0.065 & -0.055 & 0.065 & -0.055 & 0.065 \\
\hline-0.05 & 0.06 & -0.05 & 0.06 & -0.05 & 0.06 \\
\hline-0.045 & 0.055 & -0.045 & 0.055 & -0.045 & 0.055 \\
\hline-0.04 & 0.05 & -0.04 & 0.05 & -0.04 & 0.05 \\
\hline-0.035 & 0.045 & -0.035 & 0.045 & -0.035 & 0.045 \\
\hline-0.03 & 0.04 & -0.03 & 0.04 & -0.03 & 0.04 \\
\hline-0.025 & 0.035 & -0.025 & 0.035 & -0.025 & 0.035 \\
\hline-0.02 & 0.03 & -0.02 & 0.03 & -0.02 & 0.03 \\
\hline-0.015 & 0.025 & -0.015 & 0.025 & -0.015 & 0.025 \\
\hline-0.01 & 0.02 & -0.01 & 0.02 & -0.01 & 0.02 \\
\hline-0.005 & 0.015 & -0.005 & 0.015 & -0.005 & 0.015 \\
\hline 0 & 0.01 & 0 & 0.01 & 0 & 0.01 \\
\hline 0.005 & 0.005 & 0.005 & 0.005 & 0.005 & 0.00 \\
\hline .01 & 0 & 0.01 & 0 & 0.01 & 0 \\
\hline 0.015 & -0.005 & 0.015 & -0.005 & 0.015 & -0.00 \\
\hline 0.02 & -0.01 & 0.02 & -0.01 & 0.02 & -0.01 \\
\hline 0.025 & -0.015 & 0.025 & -0.015 & 0.025 & -0.01 \\
\hline 0.03 & -0.02 & 0.03 & -0.02 & 0.03 & -0.02 \\
\hline 0.035 & -0.025 & 0.035 & -0.025 & 0.035 & -0.02 \\
\hline 0.04 & -0.03 & 0.04 & -0.03 & 0.04 & -0.03 \\
\hline 0.045 & -0.035 & 0.045 & -0.035 & 0.045 & -0.03 \\
\hline 0.05 & -0.04 & 0.05 & -0.04 & 0.05 & -0.0 \\
\hline 0.055 & -0.045 & 0.055 & -0.045 & 0.055 & -0.04 \\
\hline 0.06 & -0.05 & 0.06 & -0.05 & 0.06 & -0.0 \\
\hline 0.065 & -0.055 & 0.065 & -0.055 & 0.065 & -0.05 \\
\hline 0.07 & -0.06 & 0.07 & -0.06 & 0.07 & -0.06 \\
\hline 0.075 & -0.065 & 0.075 & -0.065 & 0.075 & -0.06 \\
\hline 0.08 & -0.07 & 0.08 & -0.07 & 0.08 & -0.0 \\
\hline
\end{tabular}

